\title{
Timing of renal replacement therapy
} initiation for acute kidney injury in critically ill patients: a systematic review of randomized clinical trials with meta-analysis and trial sequential analysis

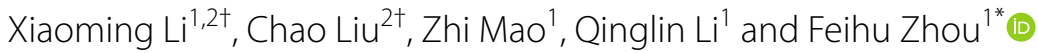

\begin{abstract}
Background: Acute kidney injury (AKI) is a common serious complication in critically ill patients. AKI occurs in up to $50 \%$ patients in intensive care unit (ICU), with poor clinical prognosis. Renal replacement therapy (RRT) has been widely used in critically ill patients with AKI. However, in patients without urgent indications such as acute pulmonary edema, severe acidosis, and severe hyperkalemia, the optimal timing of RRT initiation is still under debate. We conducted this systematic review of randomized clinical trials (RCTs) with meta-analysis and trial sequential analysis (TSA) to compare the effects of early RRT initiation versus delayed RRT initiation.
\end{abstract}

Methods: We searched databases (PubMed, EMBASE and Cochrane Library) from inception through to July 20, 2020, to identify eligible RCTs. The primary outcome was 28-day mortality. Two authors extracted the data independently. When the $R^{2}$ values $<25 \%$, we used fixed-effect mode. Otherwise, the random effects model was used as appropriate. TSA was performed to control the risk of random errors and assess whether the results in our meta-analysis were conclusive.

Results: Eleven studies involving 5086 patients were identified. Two studies included patients with sepsis, one study included patients with shock after cardiac surgery, and eight others included mixed populations. The criteria for the initiation of RRT, the definition of AKI, and RRT modalities existed great variations among the studies. The median time of RRT initiation across studies ranged from 2 to $7.6 \mathrm{~h}$ in the early RRT group and 21 to $57 \mathrm{~h}$ in the delayed RRT group. The pooled results showed that early initiation of RRT could not decrease 28-day all-cause mortality compared with delayed RRT (RR 1.01; 95\% Cl 0.94-1.09; $P=0.77 ; P^{2}=0 \%$ ). TSA result showed that the required information size was 2949. The cumulative $Z$ curve crossed the futility boundary and reached the required information size. In addition, early initiation of RRT could lead to unnecessary RRT exposure in some patients and was associated with a higher incidence of hypotension (RR 1.42; 95\% Cl 1.23-1.63; $P<0.00001 ; P^{2}=8 \%$ ) and RRT-associated infection events (RR 1.34; $\left.95 \% \mathrm{Cl} 1.01-1.78 ; P=0.04 ; P^{2}=0 \%\right)$.

\footnotetext{
*Correspondence: feihuzhou301@126.com

${ }^{\dagger}$ Xiaoming Li and Chao Liu contributed equally to this work

1 Department of Critical Care Medicine, the First Medical Centre,

Chinese People's Liberation Army General Hospital, 28 Fu-Xing Road,

Beijing 100853, People's Republic of China

Full list of author information is available at the end of the article
}

(c) The Author(s) 2021. Open Access This article is licensed under a Creative Commons Attribution 4.0 International License, which permits use, sharing, adaptation, distribution and reproduction in any medium or format, as long as you give appropriate credit to the original author(s) and the source, provide a link to the Creative Commons licence, and indicate if changes were made. The images or other third party material in this article are included in the article's Creative Commons licence, unless indicated otherwise in a credit line to the material. If material is not included in the article's Creative Commons licence and your intended use is not permitted by statutory regulation or exceeds the permitted use, you will need to obtain permission directly from the copyright holder. To view a copy of this licence, visit http://creativecommons.org/licenses/by/4.0/. The Creative Commons Public Domain Dedication waiver (http://creativeco mmons.org/publicdomain/zero/1.0/) applies to the data made available in this article, unless otherwise stated in a credit line to the data. 
Conclusions: This meta-analysis suggested that early initiation of RRT was not associated with survival benefit in critically ill patients with AKI. In addition, early initiation of RRT could lead to unnecessary RRT exposure in some patients, resulting in a waste of health resources and a higher incidence of RRT-associated adverse events. Maybe, only critically ill patients with a clear and hard indication, such as severe acidosis, pulmonary edema, and hyperkalemia, could benefit from early initiation of RRT.

Keywords: Renal replacement therapy, Acute kidney injury, Critically ill, Time, Systematic review, Meta-analysis

\section{Introduction}

Acute kidney injury (AKI) is a common serious complication of critically ill patients. AKI occurs in up to $50 \%$ patients in intensive care unit (ICU), with poor clinical prognosis [1-4]. Patients with AKI are characteristic of a rapid loss of the kidney function, which can lead to electrolyte disorder, metabolic acidosis, fluid overload, and an increase in serum uremic toxins. Renal replacement therapy (RRT) has been widely used in critically ill patients with AKI. For patients with severe complications such as acute pulmonary edema, severe acidosis, and severe hyperkalemia, RRT is the cornerstone of AKI treatment to be performed urgently $[5,6]$. However, without these urgent indications, the optimal timing of initiating RRT is still under debate. Early initiation of RRT can correct metabolic disorders, control disturbances of fluid metabolism, and remove uremic toxins quickly and effectively. However, for patients whose renal function can recover spontaneously, early initiation of RRT may not be beneficial but expose them to the risk of RRT-associated adverse events, such as hemodynamic instability, bleeding, and bloodstream infection [6-8].

Although there were several meta-analyses to evaluate whether critically ill patients with AKI can benefit from initiating RRT early, the conclusions were inconsistent and none of them included all randomized clinical trials (RCTs) up to present. Karvellas et al. conducted a meta-analysis, including two RCTs, four prospective cohort, and nine retrospective cohort, showing a beneficial impact on survival when RRT was performed at early stage [9]. However, recently published meta-analyses on this topic indicated that early initiation of RRT did not improve patient prognosis [10-12]. And a high-quality meta-analysis of RCTs with individual data of all the included patients reached the similar conclusion [13]. Recently, the largest RCT, STARRT-AKI trail, was published. Totally, 2927 critically ill patients with severe AKI were randomly assigned to accelerated-strategy group and standard-strategy group. The primary and secondary outcomes were comparable between the two groups, while more adverse events occurred in the acceleratedstrategy group [14].

Based on a sufficient number of high-quality RCTs, we conducted this systematic review of RCTs with meta-analysis and trial sequential analysis (TSA) to compare the effects of early RRT initiation versus delayed RRT initiation.

\section{Methods}

We followed the Preferred Reporting Items for Systematic Reviews and Meta-Analyses (PRISMA statement) guidelines to perform this meta-analysis [15] (see Additional file 1). No prospectively registered protocol was existed; however, search terms, data extraction, inclusion and exclusion criteria, and data synthesis were according to a plan made by our team.

\section{Eligibility criteria}

The inclusion criteria were as follows: (1) population: critically ill patients with AKI aged 18 years or older; (2) intervention: the treatment group received early RRT; (3) Comparison intervention: the control group received delayed RRT; (4) outcome: 28-day all-cause mortality, 90-day mortality, or hospital all-cause mortality were available; and (5) study design: RCT. The exclusion criteria were as follows: (1) study type was not RCT; (2) patients included children; (3) study not focused on critical illness; (4) without a clearly definition of "early" and "delayed" strategies; and (5) the reason for initiating RRT was not AKI, but others. There were no restrictions on publication language.

\section{Search strategy and selection process}

We searched PubMed, EMBASE, and the Cochrane Central Register of Controlled Trials Library database from inception through to July 20, 2020. We used key-words and free-text words which were related to AKI, RRT, critical illness and timing of initiating RRT. The detail of search strategy for PubMed is shown in Additional file 2. The reference lists of the included studies and recent review articles were hand-searched to find additional citations. Two authors (X.L and C.L) independently screened all potentially relevant citations to find studies for the final analysis. Any disagreements between two authors were resolved through discussion. 


\section{Data extraction and risk of bias assessment}

Two authors (X.L and C.L) extracted the following information in a standard form independently: the first author, study center (single-center or multicenter trial), publication year, patient characteristics (mean age of the patient, sample size, male percentage and patient population), details of RRT (criteria for RRT initiation and RRT modality), all clinical outcomes. Two authors (X.L and C.L) independently evaluated the risk of bias for each of these studies by the Cochrane risk of bias assessment tool [16]. Any disagreements were resolved by discussion, if no agreement could be reached, it would be decided by a third author (F.Z). Only when all the items were assessed as low risk bias, the study was classified as low risk of bias, otherwise the study would be considered as high risk of bias.

\section{Outcomes}

The primary outcome was 28 -day all-cause mortality. The secondary outcomes included 90-day all-cause mortality, hospital all-cause mortality, ICU all-cause mortality, number of patients who received RRT, RRT dependence at 28-day among survivors, RRT dependence at 90-day among survivors, length of hospital stay, length of ICU stay, mechanical ventilation-free days up to day 28 , RRTfree days up to day 28 , and vasopressor-free days up to day 28 . The incidence of adverse events potentially associated with RRT was also evaluated, including hypotension, any arrhythmia, bleeding events, and infection during the treatment.

\section{Statistical analysis}

For binary outcomes, we calculated the risk ratios (RRs) and $95 \%$ confidence intervals (CIs) by the Mantel-Haenszel method. For continuous outcomes, we used the inverse variance method to pool the mean differences (MDs) and 95\% CIs. Heterogeneity among the included studies was assessed using the $I^{2}$ statistic, which the $I^{2}$ values of $25 \%, 50 \%$, and $75 \%$ represented low, moderate, and high heterogeneity, respectively [17]. When the $I^{2}$ values $<25 \%$, we used the fixed-effect mode. Otherwise, the random effects model was used as appropriate. If a two-sided $\mathrm{P}$ value was less than 0.05 , the results were considered statistically significant. We used funnel plots to assess the publication bias [18]. Subgroup analyses for the primary outcome were performed based on mean age of patients in each study ( $>65$ years or $\leq 65$ years), the SOFA scores at administration $(>12$ or $\leq 12)$, and the criteria for early RRT initiation (Approximately equal to stage 2 of the KDIGO classification, approximately equal to stage 3 of the KDIGO classification, or other classification criteria subgroup) [19]. We did sensitivity analyses for the primary outcome according to publish language (excluding the study published in Chinese), risk of bias (only including studies classified as low risk of bias), and publish year (removing studies published before 2010). All statistical analyses were performed by Review Manager (version 5.3).

\section{Trial sequential analysis}

We conducted TSA to control the risk of random errors and assess whether the results in our meta-analysis were conclusive. We used a random effects model to construct the cumulative $Z$ curve. TSA was performed to maintain an overall $5 \%$ risk of a type I error. Based on previous high-quality RCTs on this topic [14, 20], we used an anticipated relative risk reduction (RRR) of $15.0 \%$ with a power of $90 \%$ to calculate the required information size to detect or reject an intervention effect. And the control event rate was adjusted according to the relevant rate of standard therapy (delayed-strategy) group in our meta-analysis. When the cumulative $Z$ curve crossed the trial sequential monitoring boundary or entered the futility area, a sufficient level of evidence for accepting or rejecting the anticipated intervention effect may have been reached, and no further studies were needed. If the $Z$ curve did not cross any of the boundaries, and the required information size had not been reached, evidence to reach a conclusion was insufficient, and more studies would be required [21].

\section{Results}

\section{Selection of included studies}

According to our search strategy, 1828 potentially studies were identified. Five hundred seventy-three duplicate publications were excluded. Thirty-seven studies were eligible for full-text reviews after screening titles and abstracts. Only eleven studies involving 5086 patients were finally included in this meta-analysis [14, 20, 22-30] (Fig. 1). Table 1 summarizes the characteristics of the included individual studies. Most studies were assessed as low risk of bias [14, 20, 22-27] (see Additional file 3). Eight studies were done in a multicenter, while three studies were done in a single-center. All other studies were published after 2010, except for one study. The main cause of AKI in the included studies was sepsis. The number of participants across studies ranged from 40 to 2927. The range of the mean age of study participants was 42.4-69. The criteria for early initiation of RRT and delayed initiation of RRT existed differences among the studies. Due to the different criteria of initiating RRT, the time of initiating RRT was different. The median time of RRT initiation across studies ranged from 2 to $7.6 \mathrm{~h}$ in the early RRT group and 21 to $57 \mathrm{~h}$ in the delayed RRT group. 


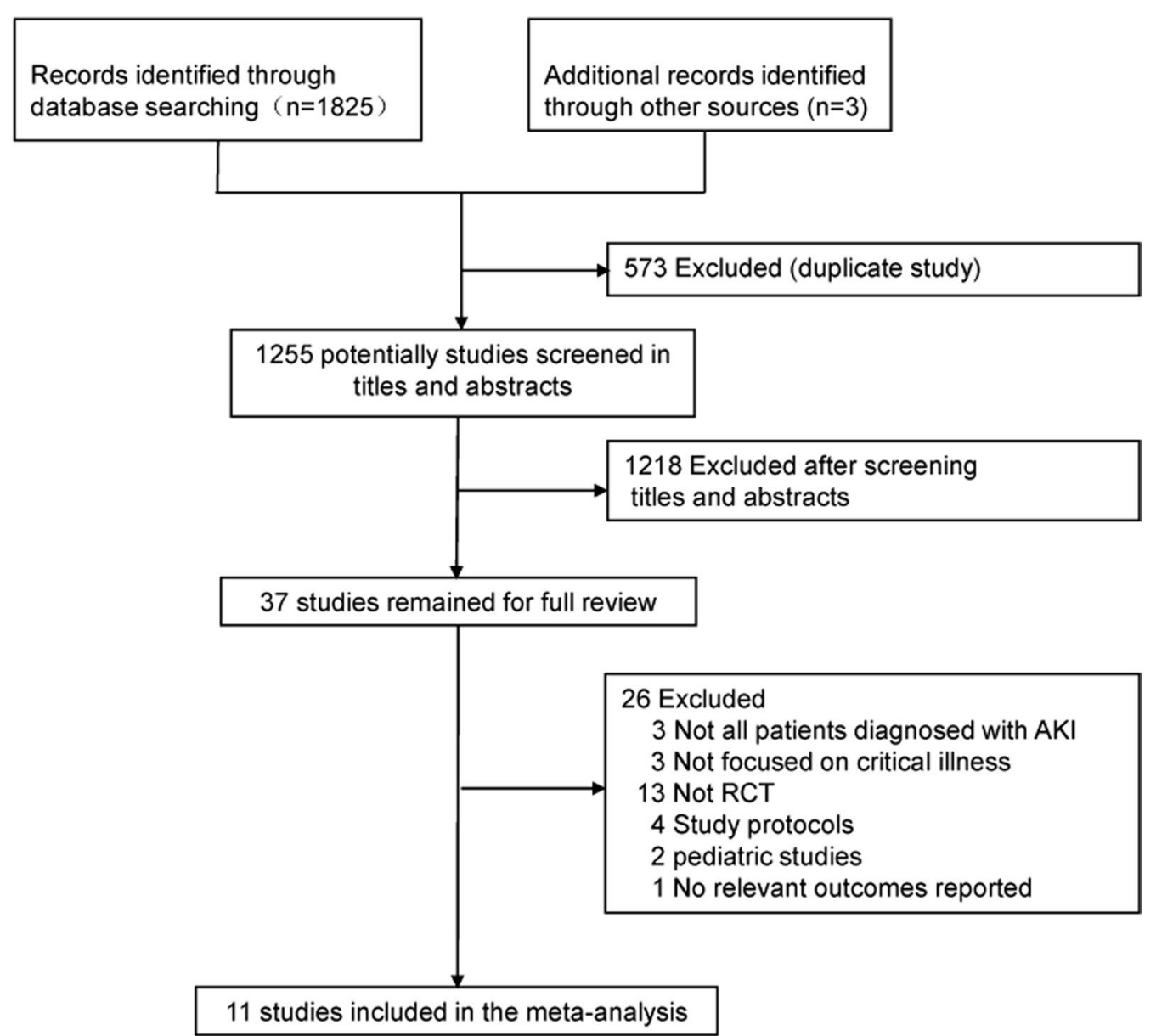

Fig. 1 Flow diagram for the identification of eligible studies

\section{Mortality}

Ten studies reported 28-day mortality [14, 20, 22-27, $29,30]$. The mortality in the early-strategy group and the delayed-strategy group was $38.4 \%$ (937 of 2437 patients) and $38.0 \%$ (928 of 2441 patients), respectively. The pooled results showed that early initiation of RRT could not decrease 28-day all-cause mortality compared with delayed initiation of RRT (RR 1.01; 95\% CI 0.94-1.09; $P=0.77 ; I^{2}=0 \%$; Fig. $2 \mathrm{a}$ ). There was no obvious asymmetry in funnel plots by visually inspecting (see Additional file 4). The TSA result showed that the required information size was 2949 . The cumulative $Z$ curve crossed the futility boundary and reached the required information size, suggesting that a RRR of $15 \%$ or greater could be rejected (Fig. 3a).

There were no significant differences in 90-day mortality (RR 1.02; 95\% CI 0.92-1.13; $P=0.75 ; I^{2}=37 \% ; 4077$ participants, 6 studies, Fig. 2b), ICU mortality (RR 1.00; 95\% CI 0.90-1.10; $P=0.94 ; I^{2}=0 \% ; 3321$ participants, 4 studies, Fig. 2c), or hospital mortality (RR 1.02; 95\% CI
0.95-1.10; $P=0.51 ; I^{2}=4 \% ; 4337$ participants, 8 studies, Fig. 2d) between the two groups. For 90-day mortality, TSA indicated that only $74.6 \%$ (4077 of 5464 patients) of the required information size was accrued. The cumulative $Z$ curve did not cross the conventional boundary or the sequential monitoring boundary. However, the cumulative $Z$ curve crossed the futility boundary (Fig. 3b). In terms of hospital mortality, the cumulative $Z$ curve crossed the futility boundary and reached the required information size (Fig. 3c).

\section{Number of patients who received RRT}

$97.2 \%$ (2468 of 2539 ) of patients in the early-strategy group and $62.5 \%$ (1591 of 2547) of patients in the delayed-strategy group received RRT during therapy. Delayed initiation of RRT could significantly reduce the number of patients receiving RRT (RR 1.52; 95\% CI 1.30$1.78 ; P<0.00001 ; I^{2}=95 \%$; see Additional file $5 \mathrm{a}$ ), indicating that renal function can recover spontaneously in a considerable proportion of AKI patients. 


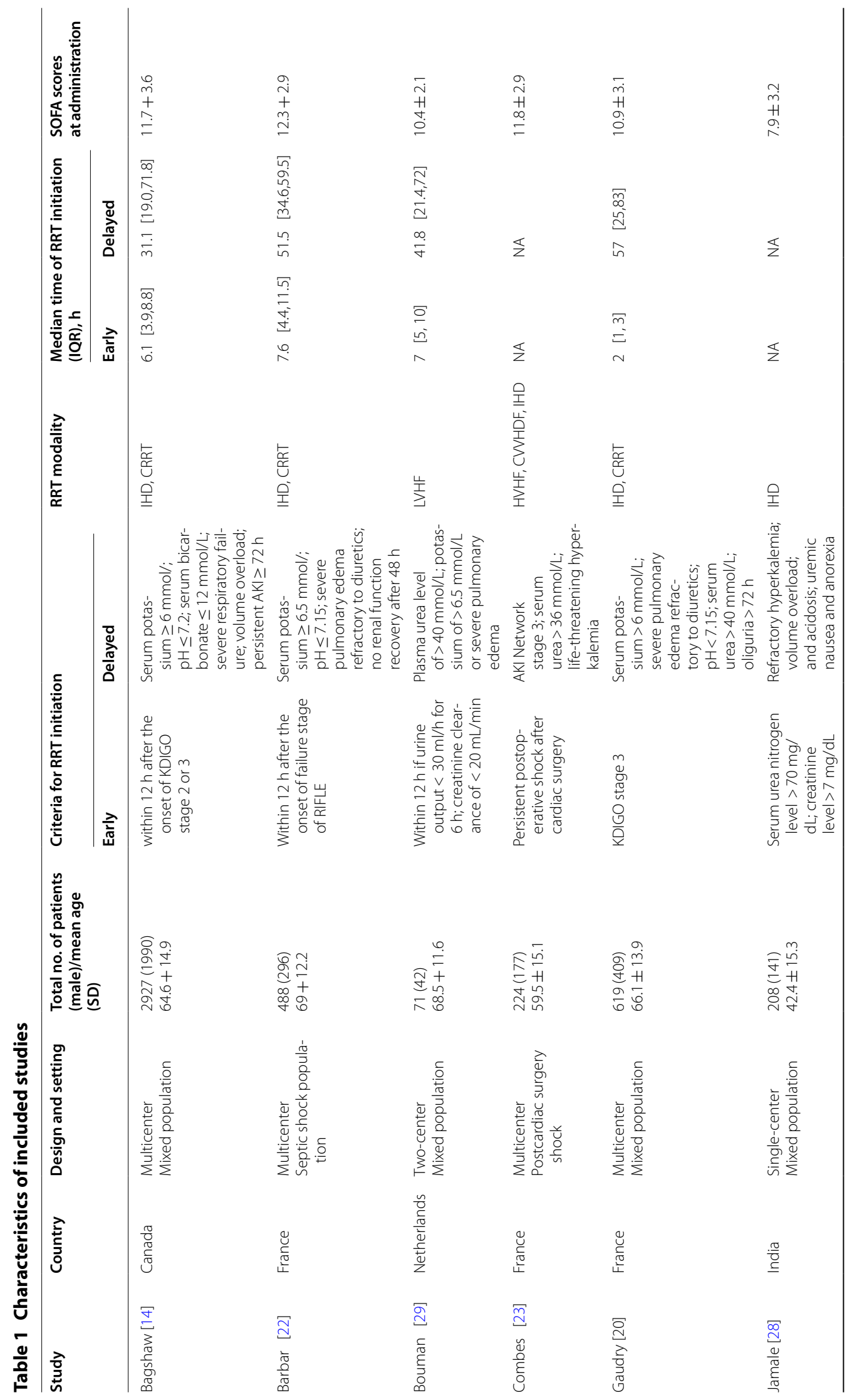




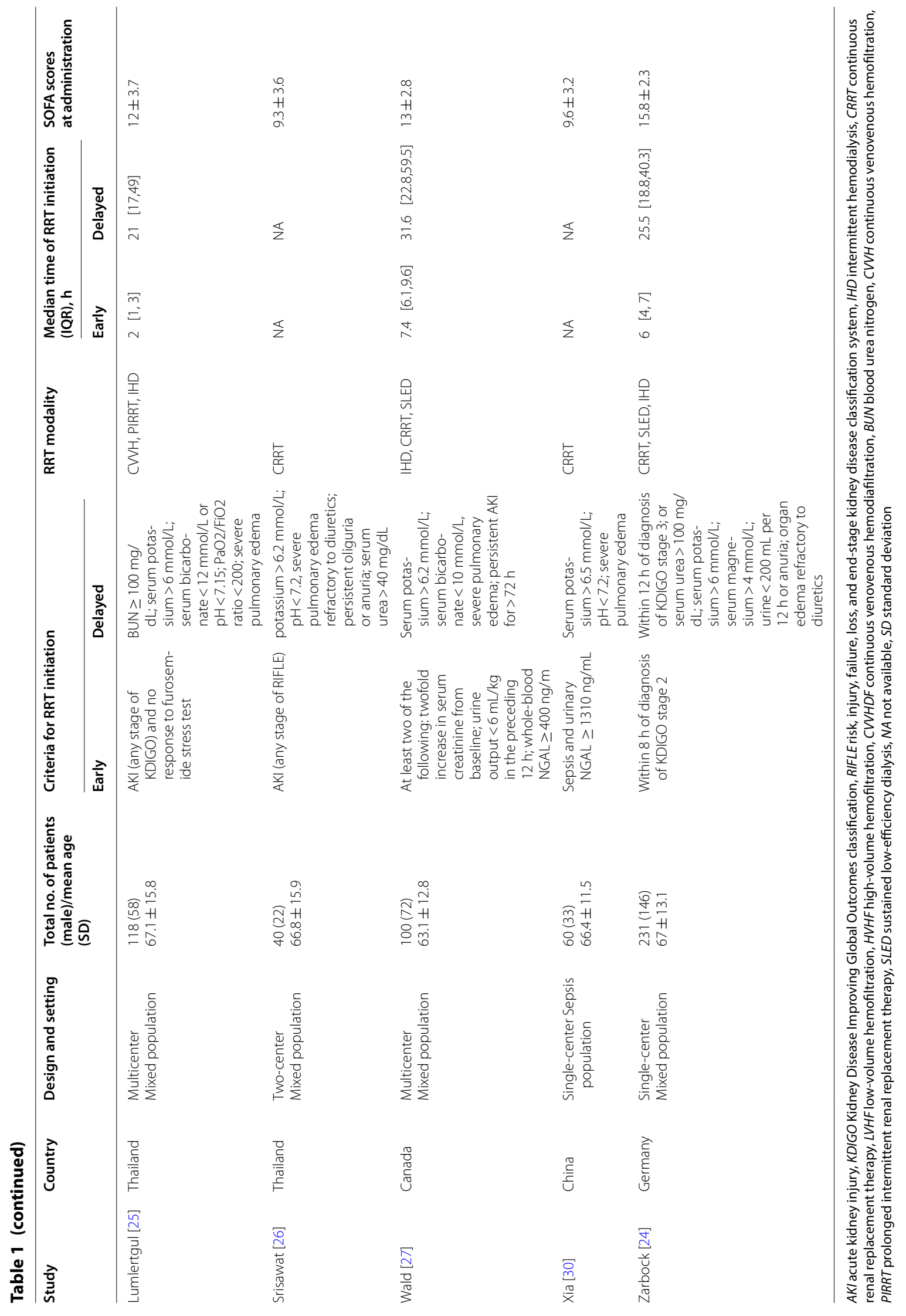




\section{a 28-day mortality}

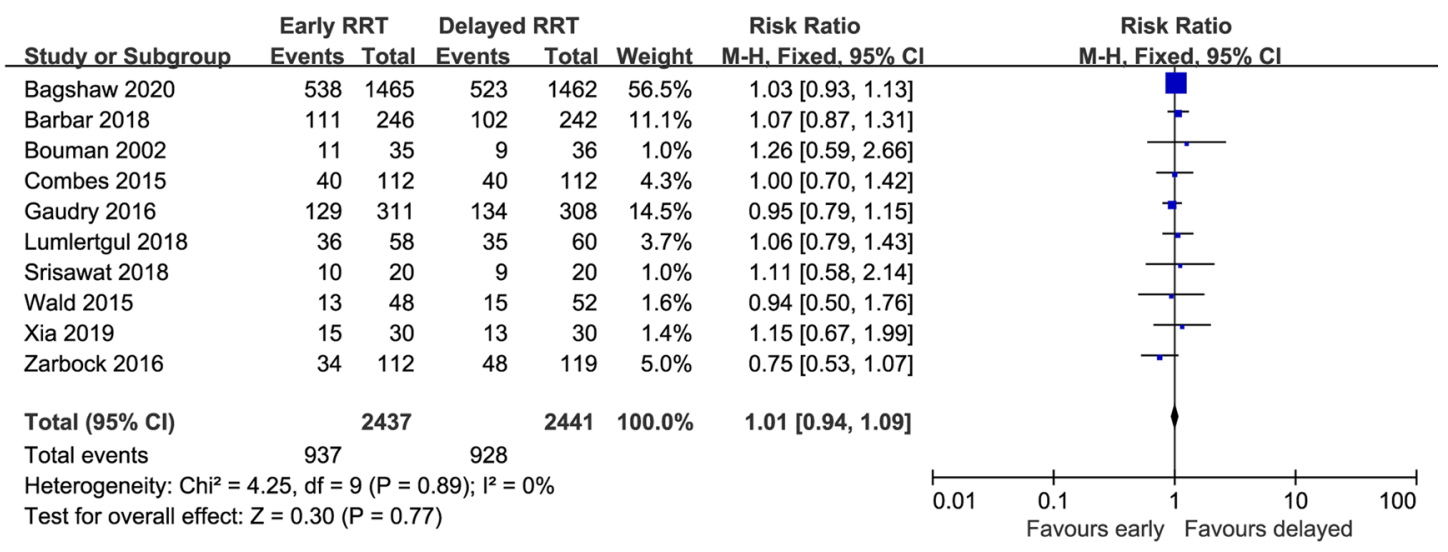

\section{b 90-day mortality}

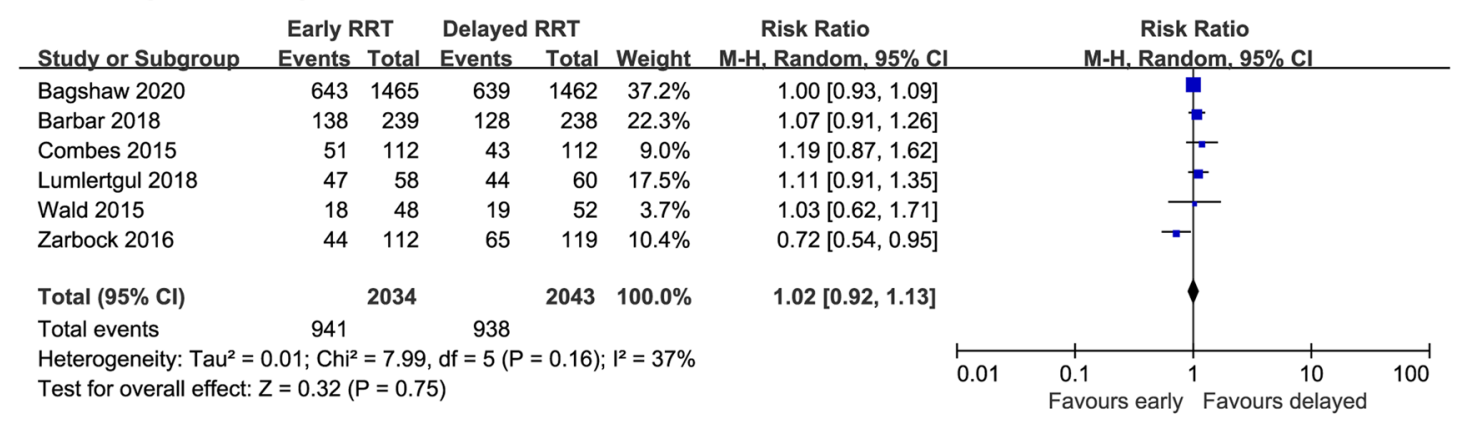

\section{c ICU mortality}

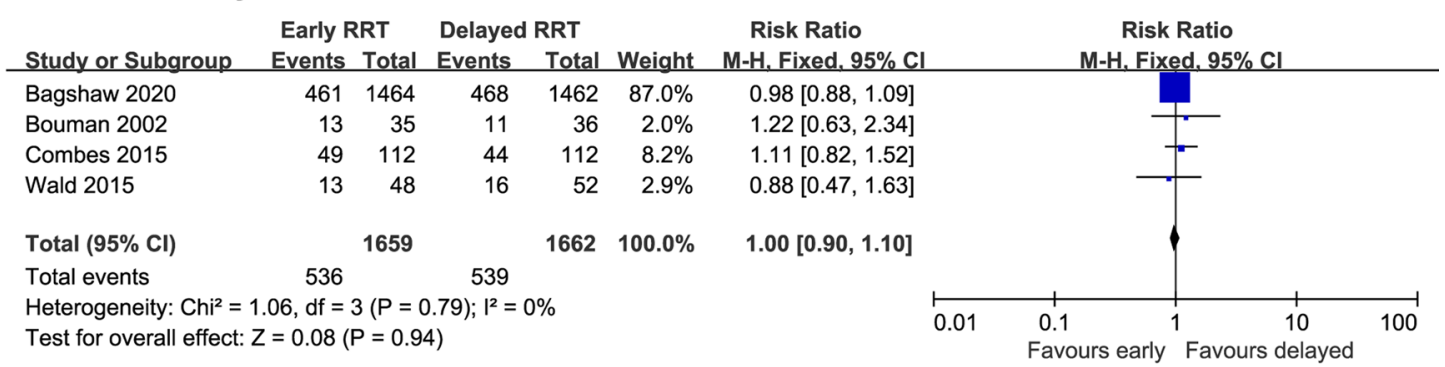

\section{d hospital mortality}

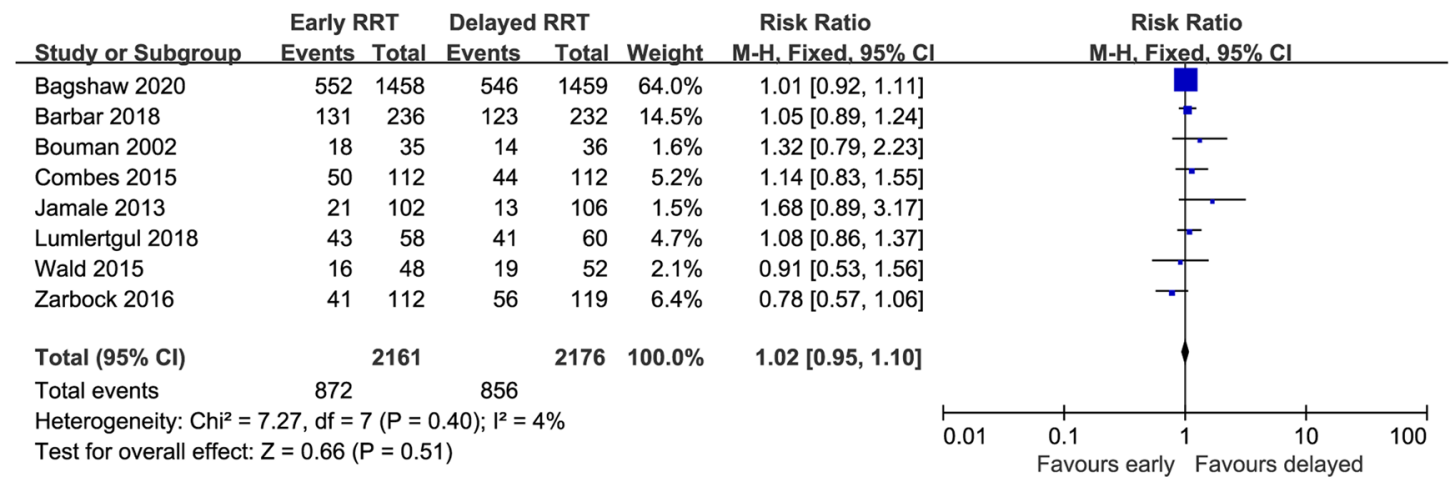

Fig. 2 Forest plot of comparison: early RRT initiation group versus delayed RRT initiation group. a 28-day mortality; b 90-day mortality; c ICU mortality; d. hospital mortality 


\section{(See figure on next page.)}

Fig. 3 Trial sequential analysis. a-c The cumulative $Z$ curve (complete blue line) was constructed using a random effects model. Etched red line shows conventional test boundary. Complete red line represents the trial sequential monitoring boundary. a. TSA for 28-day mortality. A diversity-adjusted information size of 2949 patients was calculated on the basis of using $a=0.05$ (two sided), $\beta=0.10$ (power $90 \%$ ), an anticipated relative risk reduction (RRR) of $15.0 \%$, and a control event rate of $38.0 \%$. The cumulative $Z$ curve crossed the futility boundary and reached the required information size. $\mathbf{b}$ TSA for 90 -day mortality. A diversity-adjusted information size of 5464 patients was calculated on the basis of using $a=0.05$ (two sided), $\beta=0.10$ (power 90\%), an anticipated relative risk reduction (RRR) of $15.0 \%$, and a control event rate of $45.9 \%$. The cumulative $Z$ curve crossed the futility boundary. c. TSA for hospital mortality. A diversity-adjusted information size of 3262 patients was calculated on the basis of using $a=0.05$ (two sided), $\beta=0.10$ (power 90\%), an anticipated relative risk reduction (RRR) of 15.0\%, and a control event rate of $39.3 \%$. The cumulative $Z$ curve crossed the futility boundary and reached the required information size

\section{RRT dependence among survivors}

Six studies [20, 22-24, 26, 29] with 984 patients reported the number of patients who required RRT among survivors at 28 days, and five studies [14, 22-24, 27] with 2153 patients reported the number of patients who required RRT among survivors at 90 days. For survivors requiring RRT, no significant differences were detected between the two groups at 28 days (RR 0.97; 95\% CI 0.58-1.60; $P=0.89 ; I^{2}=46 \%$; see Additional file $5 \mathrm{~b}$ ) and 90 days (RR 1.24; $95 \%$ CI 0.70-2.21; $P=0.46 ; I^{2}=30 \%$; see Additional file $5 \mathrm{c}$ ), indicating that timing of RRT initiation was not associated with renal function recovery.

\section{Length of ICU stay and hospital stay}

Data on the length of ICU stay and hospital stay were available in five studies [22, 24, 25, 27, 29] and seven studies [20, 22, 24, 25, 27-29], respectively. The pooled results showed that RRT initiation time was not associated with the length of ICU stay (MD - 0.06; 95\% CI -1.59 to $1.48 ; P=0.94 ; I^{2}=0 \% ; 1008$ participants; see Additional file $5 \mathrm{~d}$ ) or hospital stay (MD -2.88 ; $95 \% \mathrm{CI}$ -6.57 to $0.81 ; P=0.13 ; I^{2}=41 \% ; 1835$ participants; see Additional file 5e).

\section{Mechanical ventilation-free days, RRT-free days and vasopressor-free days up to day $\mathbf{2 8}$}

Eight studies reported mechanical ventilation-free days up to day 28 [14, 20, 22-26, 29]. Six studies reported RRT-free days up to day 28 [20, 22, 23, 25-27]. Four studies reported vasopressor-free days up to day 28 $[14,20,22,23]$. Meta-analysis showed that there were no significant differences in terms of mechanical ventilation-free days at 28 days (MD $0.47 ; 95 \%$ CI -0.42 to $1.36 ; P=0.30 ; I^{2}=31 \%$; 4718 participants; see Additional file $5 \mathrm{f}$ ), RRT-free days at 28 days (MD - 1.13; $95 \% \mathrm{CI}-2.36$ to $0.10 ; P=0.07 ; I^{2}=21 \% ; 1589$ participants; see Additional file $5 \mathrm{~g}$ ), or vasopressor-free days at 28 days (MD $0.39 ; 95 \% \mathrm{CI}-0.48$ to $1.25 ; P=0.38$;
$I^{2}=0 \% ; 4258$ participants; see Additional file 5h) between the early-strategy group and the delayed-strategy group.

\section{Adverse events during treatment}

Seven studies reported hypotension events [14, 22-25, $27,28]$. There were 336 patients $(15.7 \%)$ who developed hypotension among 2143 patients in the early-strategy group and 237 patients (11.0\%) who developed hypotension among 2153 patients in the delayed-strategy group. According to the results, early RRT initiation leads to more hypotension events than delayed RRT initiation (RR 1.42; $95 \%$ CI 1.23 to $1.63 ; P<0.00001 ; I^{2}=8 \%$; Fig. 4 a). Six studies involving 4460 patients reported the RRT-associated infection during treatments [14, 20, 22, 25, 27, 28]. Infection occurred 99 patients $(4.4 \%)$ in the early-strategy group and 73 patients (3.3\%) in the delayed-strategy group. Early RRT initiation resulted in a significantly higher incidence of RRT-associated infection events (RR 1.34; $95 \%$ CI 1.01 to $1.78 ; P=0.04 ; I^{2}=0 \%$; Fig. $\left.4 \mathrm{~b}\right)$. In terms of arrhythmia and bleeding events, the pooled RRs were 1.23 (95\% CI 0.85 to $1.79 ; P=0.27 ; I^{2}=50 \% ; 4483$ participants; 6 studies; Fig. 4c) and 0.96 (RR 0.96; 95\% CI 0.79 to $1.17 ; P=0.72 ; I^{2}=1 \%$; 4755 participants; 8 studies; Fig. 4d), respectively. There were no statistical differences between the two groups.

\section{Subgroup analyses and sensitivity analyses}

From the subgroup analyses of the primary outcome, we found that the mean age of patients in each study ( $>65$ years or $\leq 65$ years), the SOFA scores at administration (>12 or $\leq 12)$, and the different criteria for early RRT initiation had no significant effect on 28-day all-cause mortality. Sensitivity analyses according to publish language (excluding the study published in Chinese), risk of bias (only including studies classified as low risk of bias), and publish year (removing studies published before 2010) did not alter the conclusion of the main analyses. The detailed results about subgroup analyses and sensitivity analyses are presented in Table 2 and Additional file 6 . 
Li et al. Crit Care

(2021) 25:15

Page 9 of 15

a

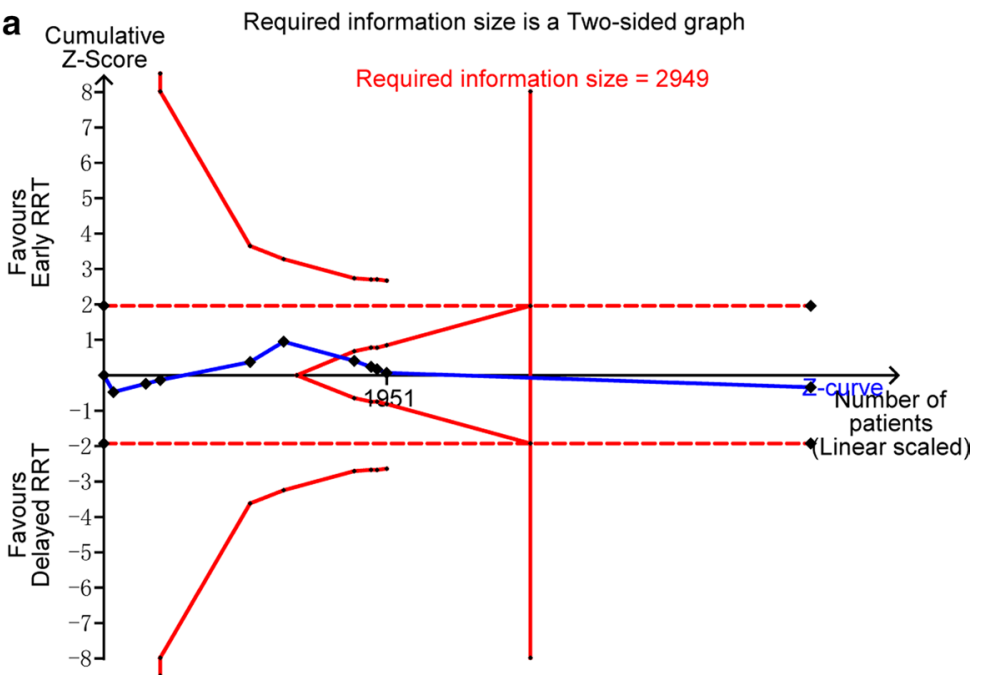

b
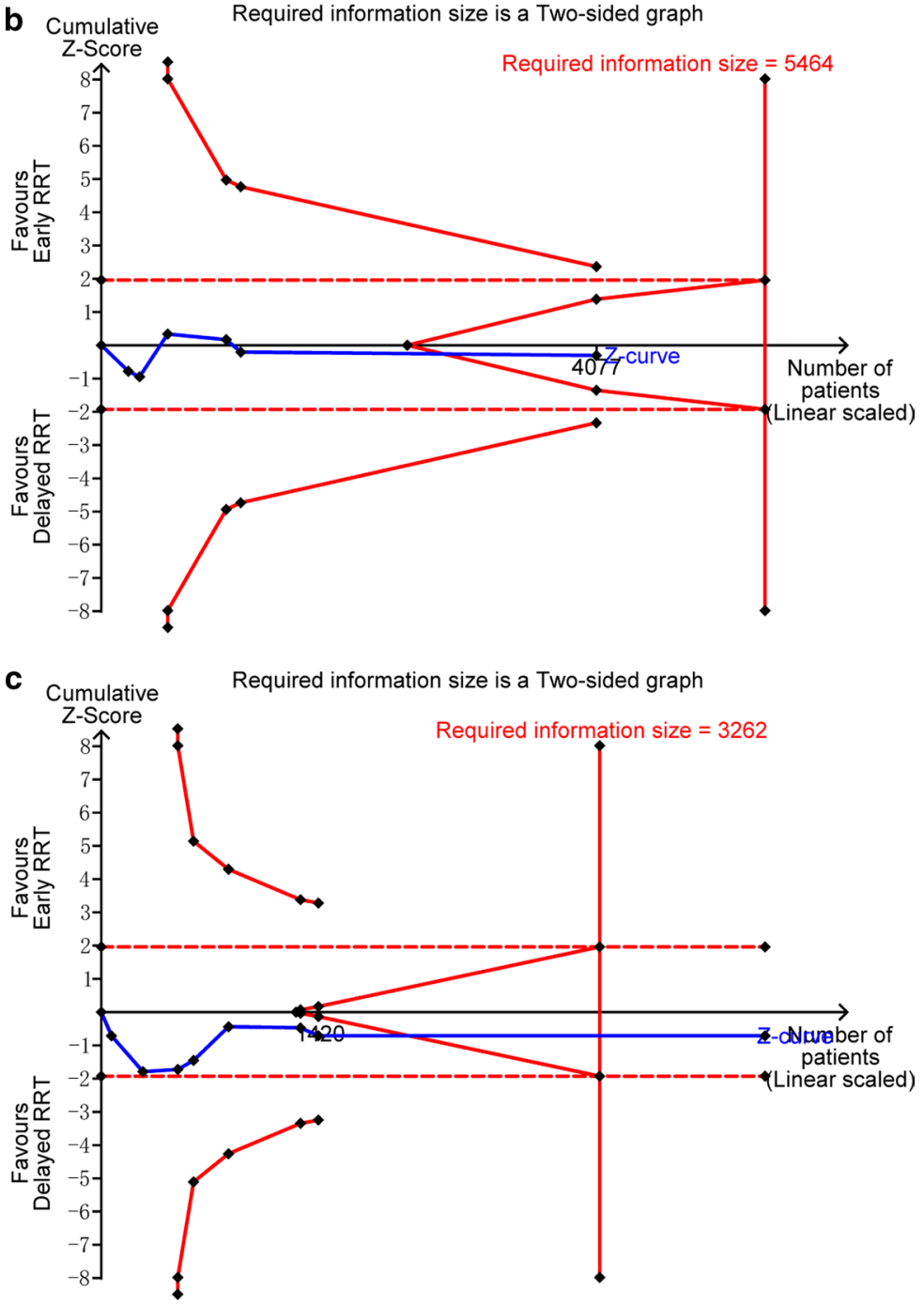


\section{a Hypotension}

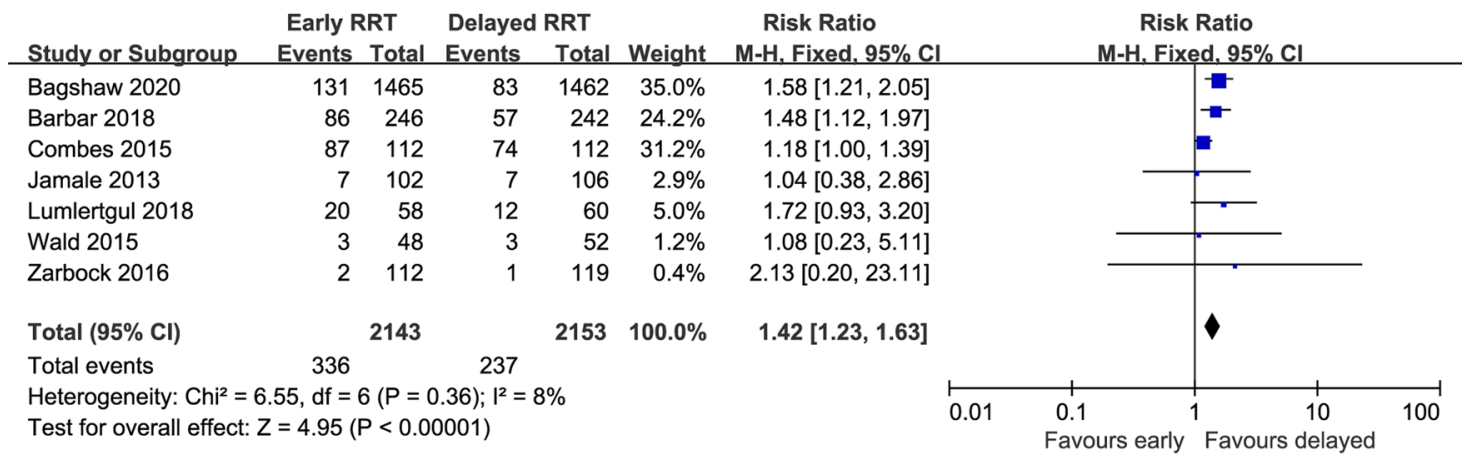

\section{b Infection}

$\begin{array}{llll}\text { Early RRT } & \text { Delayed RRT } & \text { Risk Ratio } & \text { Risk Ratio }\end{array}$

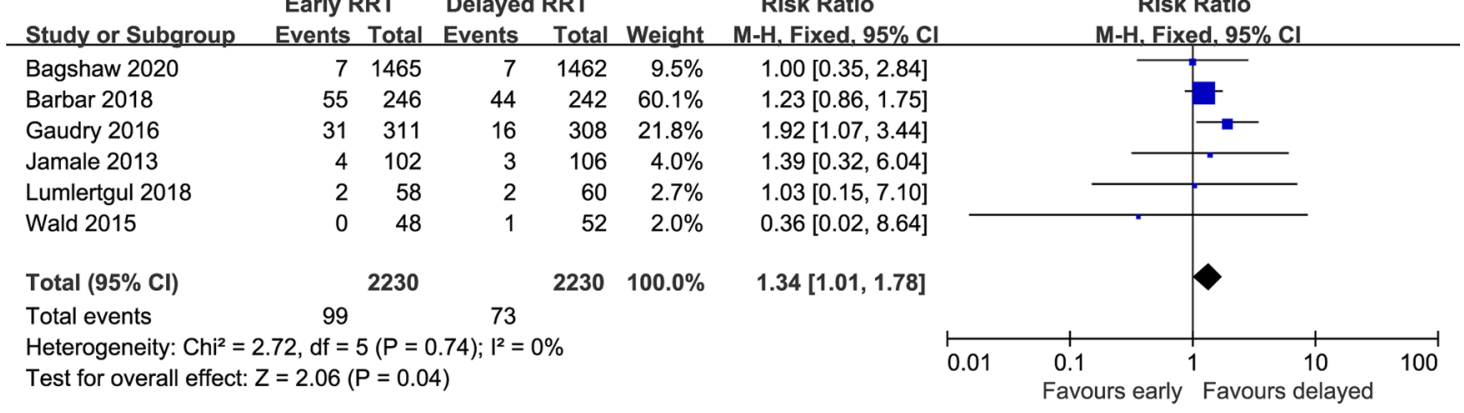

\section{c Arrhythmia}

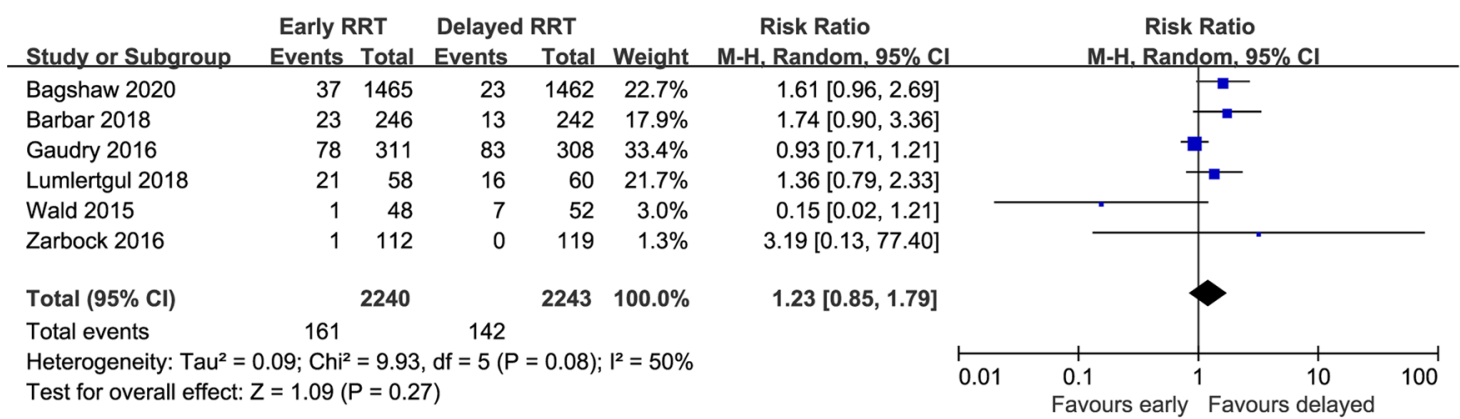

\section{d Bleeding events}

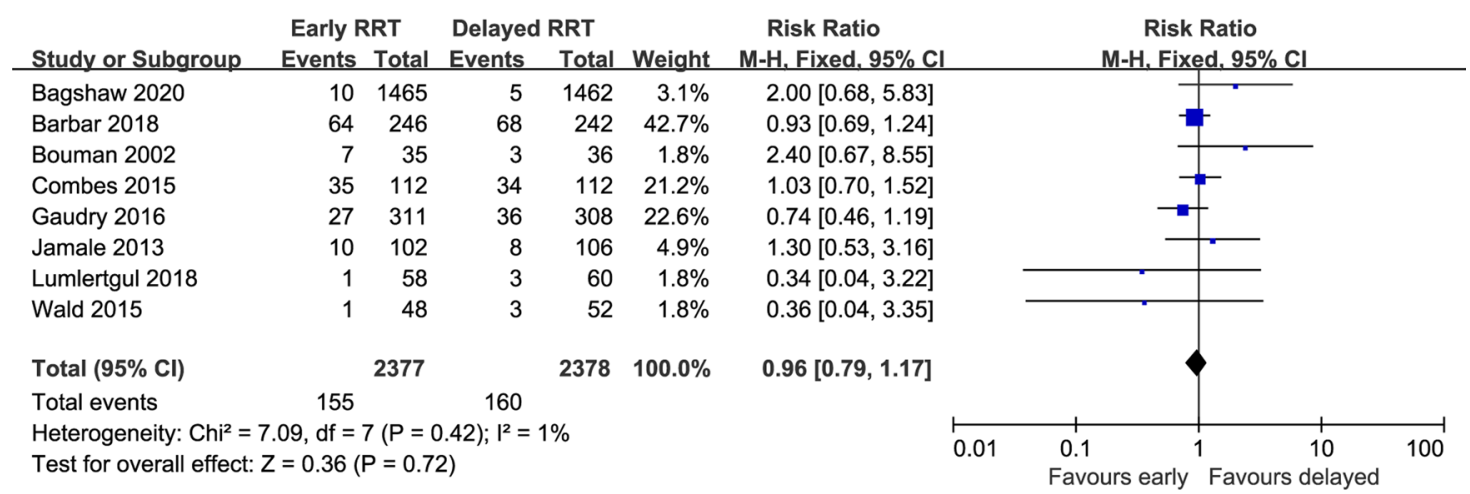

Fig. 4 Forest plot of comparison: early RRT initiation group versus delayed RRT initiation group. a Hypotension; $\mathbf{b}$ infection; c arrhythmia; $\mathbf{d}$ bleeding events 


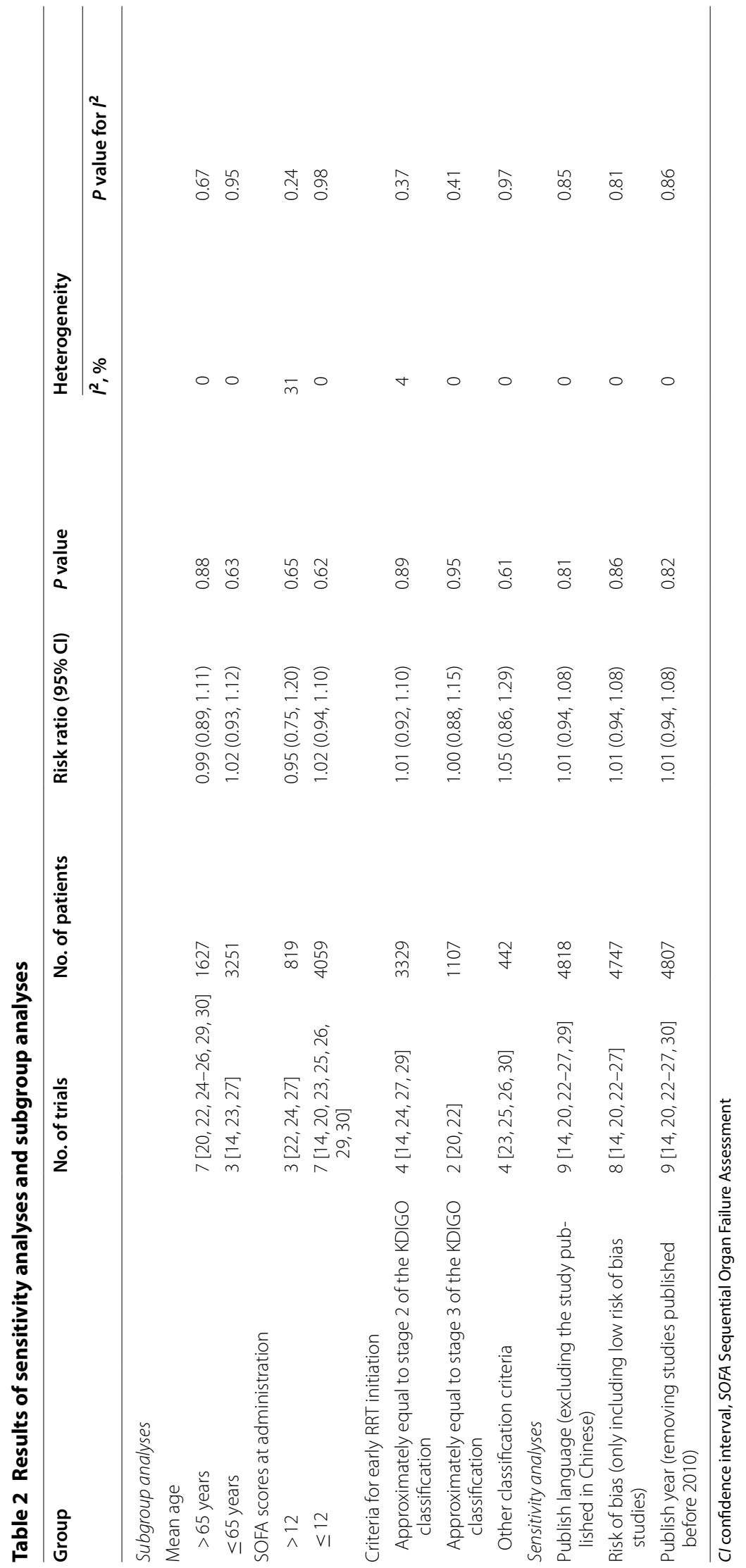




\section{Discussion}

This systematic review and meta-analysis included 11 studies comparing delayed versus early initiation of RRT for AKI in critically ill patients. The pooled results showed that early initiation of RRT was not associated with survival benefit in critically ill patients with AKI. The TSA results indicated a RRR of $15 \%$ or greater could be rejected with respect to 28-day, 90-day, or hospital mortality. In addition, early initiation of RRT could lead to unnecessary RRT exposure in some patients, resulting in a higher incidence of RRT-associated adverse events, including hypotension and infection.

Over the past few decades, RRT has become more sophisticated, with more modalities available, each with its own merits in particular situations [8]. RRT can be life-saving by correcting metabolic disorders in patients with severe acidosis and hyperkalemia, controlling disturbances of fluid metabolism in patients with severe pulmonary edema, and removing toxins and circulating inflammatory cytokines in patients with severe sepsis. We can learn from the inclusion criteria for each of the included studies that two studies included patients with sepsis, one study included patients with shock after cardiac surgery, and the other eight studies included mixed populations (see Additional file 7). Causes and pathophysiological mechanisms of AKI were highly variable in different studies, such as renal hypoperfusion, nephrotoxin exposure, ischemic reperfusion injury, and an increase in the level of circulating inflammatory cytokines. To our knowledge, the prognosis of RRT for AKI induced by different causes may be different. Moreover, the criteria for the initiation of RRT, the definition of AKI and RRT modalities existed great variations among the included studies. Therefore, we should be cautious with the results of this study.

So far, this is the only meta-analysis including the STARRT-AKI trial [14]. Our results were consistent with the results of most previous meta-analyses except three, which reported early initiation of RRT may have significant benefit on survival $[9,31,32]$. However, a considerable proportion of the included studies in these three reviews were non-RCTs, meaning that the data were prone to confounding factors. Another two meta-analyses with TSA of RCTs conducted by Moreira et al. and Feng et al. failed to establish sufficient and conclusive evidences, because the cumulative $Z$ curve did not cross the conventional boundary, the trial sequential monitoring boundary and the futility boundary, and the required information size was not reached [33, 34]. However, in our meta-analysis, the cumulative $Z$ curve crossed the futility boundaries, suggesting the results that early initiation of RRT was not associated with a lower mortality were reliable.
Hemodynamic instability is a common complication during RRT, which can increase hospital mortality and limit kidney recovery $[35,36]$. Many factors contribute to hemodynamic instability, including excessive ultrafiltration, rapid osmotic/oncotic shifts, decreased cardiac output, and decreased peripheral resistance [37]. The incidence of hypotension was $15.7 \%$ and $11.0 \%$ in the early-strategy group and in the delayed-strategy group, respectively. We can learn from Table 1 that studies which reported hypotension events all involved intermittent hemodialysis (IHD), which was more likely to result in hemodynamic instability than CRRT. A significant difference detected between the two groups may be due to more patients in the early-strategy group exposure to RRT (2468 of 2539 patients) compared with the delayedstrategy group (1591 of 2547 patients). However, none of the included studies reported the mode of RRT when the hypotension occurred. Therefore, we failed to find the association between RRT mode and hypotension in this meta-analysis. There were no statistical significances in hospital mortality and kidney recovery between the two groups, but hospital mortality and 90-day RRT dependence rates were higher in the early RRT group than the delayed RRT group. A remarkable higher incidence of RRT-associated infection events was also found in the early RRT group. Patients treated with RRT are more susceptible to infection, as they are exposure to catheters and invasive treatments $[38,39]$. Moreover, RRT may enhance the elimination of antibiotics, leading to suboptimal antibiotic concentrations [40].

In this meta-analysis, only $62.5 \%$ patients in the delayed-strategy group received RRT. Although fewer patients received RRT in the delayed-strategy group compared to the early-strategy group, the clinical outcomes were comparable between the two groups. In addition, our results showed that delayed RRT initiation could reduce the incidence of RRT-associated adverse events. Undoubtedly, unnecessary RRT will increase the workload of medical staff, augment treatment costs, and waste health resources. Therefore, it is reasonable to assume that delayed initiation of RRT is a preferable approach for critically ill patients with AKI.

As shown in Table 1, the criteria for initiating RRT and definition of AKI were associated with great variations among the included studies. Timing of RRT initiation was determined by AKI stage, biochemical marker level or urine output. AKI was defined by the RIFLE (risk, injury, failure, loss, and end-stage) criteria, the AKIN (AKI Network) criteria, or the KDIGO (Kidney Disease: Improving Global Outcomes) criteria. One problem was that patients who were classified into the early-strategy group in one study might be classified into the delayed-strategy group in another. Despite the definition of early RRT had 
differences among the included studies, the criteria for early RRT initiation were similar in some studies. And the subgroup analyses based on the criteria for early RRT initiation also showed that early RRT could not decrease 28-day all-cause mortality compared with delayed RRT. Although there were differences in the definition of the delayed RRT, most of studies initiated RRT when patients were with severe complications such as severe pulmonary edema, severe acidosis, and severe hyperkalemia. It is reasonable for us to assume that the optimal timing of initiating RRT is when patients are with severe complications. It is also worth noting that although there are a variety of criteria for initiating RRT, it is mainly based on renal function indicators at present. RRT cannot only influence renal function, but also have an effect on other organs, such as liver function, cardiac function, and so on $[41,42]$. Perhaps establishing a scoring system based on systemic multi-organ functions to find the best cutoff time initiating RRT is the way forward, just like Sequential Organ Failure Assessment (SOFA) score and Acute Physiology and Chronic Health Evaluation II (APACHE II) score.

The strengths of our study are as follows: First, we only included RCTs and most of the included studies were assessed as low risk of bias. Second, we comprehensively evaluated the effect of RRT initiation timing on clinical outcomes, including mortality, renal function recovery, various adverse events, and so on. Third, we performed TSA to determine whether the evidences in our research were reliable. Notwithstanding the aforementioned, there are several limitations in our study. The main limitation is the criteria for the initiation of RRT had great variations among the included studies. Second, we did not perform subgroup analyses according to RRT modalities, delivered dialysis dose. The choice of the RRT modality in most included studies were prescribed and monitored according to national guidelines. Some patients received CRRT at the outset, but may switch to other RRT modalities depending to their conditions. We tried to find whether the choice of RRT modality may influence the results. However, since this was a secondary analysis study, the individual patient data was not available. We cannot further analysis the effect of RRT modality on outcomes.

\section{Conclusions}

This meta-analysis suggested that early initiation of RRT was not associated with survival benefit in critically ill patients with AKI. In addition, early initiation of RRT could lead to unnecessary RRT exposure in some patients, resulting in a waste of health resources and a higher incidence of RRT-associated adverse events. Maybe, only critically ill patients with a clear and hard indication, such as severe acidosis, pulmonary edema, and hyperkalemia could benefit from early initiation of RRT.

\section{Key messages}

1. Early initiation of RRT was not associated with survival benefit in critically ill patients with AKI.

2. Early initiation of RRT could lead to unnecessary RRT exposure in some patients, resulting in a waste of health resources and a higher incidence of RRTassociated adverse events, including hypotension and infection.

3. Delayed initiation of RRT might be safe in the absence of life-threatening conditions, such as acute pulmonary edema, severe acidosis, and severe hyperkalemia.

\section{Supplementary Information}

The online version contains supplementary material available at https://doi. org/10.1186/s13054-020-03451-y.

Additional file 1: PRISMA checklist.

Additional file 2: Search strategy terms and results.

Additional file 3: Risk of bias graph and risk of bias summary graph.

Additional file 4: Funnel plots: a. Funnel plot to evaluate potential publication bias for 28-day mortality; b. Funnel plot to evaluate potential publication bias for 90-day mortality; c. Funnel plot to evaluate potential publication bias for ICU mortality; d. Funnel plot to evaluate potential publication bias for hospital mortality.

Additional file 5: Forest plot of the secondary outcomes: a. Number of patients who received RRT; b. RRT dependence among survivors at 28 days; c. RRT dependence among survivors at 90 days; $d$. The length of ICU stay; e. The length of hospital stay; f. Mechanical ventilation-free days at 28 days; g. RRT-free days at 28 days; h. Vasopressor-free days at 28 days.

Additional file 6: Forest plot of the subgroup analyses and sensitivity analyses: a.Subgroup analyses for 28-day mortality divided by the mean age of participants in each study; b. Subgroup analyses for 28-day mortality divided by the SOFA scores at administration; c. Subgroup analyses for 28-day mortality divided by the criteria for early RRT initiation; $d$. Sensitivity analyses according to publish language (excluding the study published in Chinese); e. Sensitivity analyses according to risk of bias (only including studies classified as low risk of bias); f. Sensitivity analyses according to publish year (removing studies published before 2010).

Additional file 7: The inclusion criteria for each of the included studies in this meta-analysis.

\section{Abbreviations}

AKI: Acute kidney injury; APACHE II: Acute Physiology and Chronic Health Evaluation II; AKIN: Acute kidney injury network; ICU: Intensive care unit; IHD: Intermittent hemodialysis; KDIGO: Kidney disease, improving global outcomes; PRISMA: Preferred reporting items for systematic reviews and meta-analyses; RRR: Relative risk reduction; RRT: Renal replacement therapy; RCTs: Randomized clinical trials; RIFLE: Risk, injury, failure, loss, and end-stage; SOFA: Sequential Organ Failure Assessment; TSA: Trial sequential analysis. 


\section{Acknowledgements}

We thank all researchers, patients, and surrogates involved in the individual trials.

\section{Authors' contributions}

XML conceived of the study, participated in the design, collected the data, performed statistical analyses and drafted the manuscript. CL participated in the design, collected the data, performed statistical analyses, and helped to draft the manuscript. ZM participated in the design and helped to revise the manuscript critically for important intellectual content. QLL collected the data and performed statistical analyses. FHZ conceived of the study, participated in the design, and revised the manuscript critically for important intellectual content. All authors read and approved the final manuscript.

\section{Funding}

None.

\section{Availability of data and materials}

All data generated or analyzed during this study are included in this published article (and its supplementary information files).

\section{Ethics approval and consent to participate}

Not applicable.

\section{Consent for publication}

Not applicable.

\section{Competing interests}

The authors declare that they have no competing interests.

\section{Author details}

${ }^{1}$ Department of Critical Care Medicine, the First Medical Centre, Chinese People's Liberation Army General Hospital, 28 Fu-Xing Road, Beijing 100853, People's Republic of China. ${ }^{2}$ Medical School of Chinese PLA, Beijing, People's Republic of China.

Received: 2 August 2020 Accepted: 22 December 2020

Published online: 06 January 2021

\section{References}

1. Hoste EA, Bagshaw SM, Bellomo R, Cely CM, Colman R, Cruz DN, Edipidis K, Forni LG, Gomersall CD, Govil D, et al. Epidemiology of acute kidney injury in critically ill patients: the multinational AKI-EPI study. Intensive Care Med. 2015:41(8):1411-23.

2. Soliman IW, Frencken JF, Peelen LM, Slooter AJ, Cremer OL, van Delden JJ, van Dijk D, de Lange DW. The predictive value of early acute kidney injury for long-term survival and quality of life of critically ill patients. Crit Care. 2016:20(1):242

3. Horkan CM, Purtle SW, Mendu ML, Moromizato T, Gibbons FK, Christopher KB. The association of acute kidney injury in the critically ill and postdischarge outcomes: a cohort study*. Crit Care Med. 2015:43(2):354-64.

4. Ronco C, Bellomo R, Kellum JA. Acute kidney injury. Lancet. 2019;394(10212):1949-64

5. Khwaja A. KDIGO clinical practice guidelines for acute kidney injury. Nephron Clin Pract. 2012;120(4):c179-184.

6. Matuszkiewicz-Rowinska J, Malyszko J. Acute kidney injury, its definition, and treatment in adults: guidelines and reality. Pol Arch Int Med 2020.

7. Shiao CC, Huang TM, Spapen HD, Honore PM, Wu VC. Optimal timing of renal replacement therapy initiation in acute kidney injury: the elephant felt by the blindmen? Crit Care. 2017;21(1):146.

8. Rachoin JS, Weisberg LS. Renal Replacement Therapy in the ICU. Crit Care Med. 2019:47(5):715-21.

9. Karvellas CJ, Farhat MR, Sajjad I, Mogensen SS, Leung AA, Wald R, Bagshaw SM. A comparison of early versus late initiation of renal replacement therapy in critically ill patients with acute kidney injury: a systematic review and meta-analysis. Crit Care. 2011;15(1):R72.

10. Pasin L, Boraso S, Tiberio I. Early initiation of renal replacement therapy in critically ill patients: a meta-analysis of randomized clinical trials. BMC Anesthesiol. 2019;19(1):62.
11. Yang XM, Tu GW, Zheng JL, Shen B, Ma GG, Hao GW, Gao J, Luo Z. A comparison of early versus late initiation of renal replacement therapy for acute kidney injury in critically ill patients: an updated systematic review and meta-analysis of randomized controlled trials. BMC Nephrol. 2017;18(1):264.

12. Lai TS, Shiao CC, Wang JJ, Huang CT, Wu PC, Chueh E, Chueh SJ, Kashani K, Wu VC. Earlier versus later initiation of renal replacement therapy among critically ill patients with acute kidney injury: a systematic review and meta-analysis of randomized controlled trials. Ann Intensive Care. 2017;7(1):38

13. Gaudry S, Hajage D, Benichou N, Chaibi K, Barbar S, Zarbock A, Lumlertgul N, Wald R, Bagshaw SM, Srisawat N, et al. Delayed versus early initiation of renal replacement therapy for severe acute kidney injury: a systematic review and individual patient data meta-analysis of randomised clinical trials. Lancet. 2020;395(10235):1506-15.

14. Investigators S-A, Canadian Critical Care Trials Group tA, New Zealand Intensive Care Society Clinical Trials Group tUKCCRGtCNTN, the Irish Critical Care Trials G, Bagshaw SM, Wald R, Adhikari NKJ, Bellomo R, da Costa BR, Dreyfuss D, et al. Timing of initiation of renal-replacement therapy in acute kidney injury. N Engl J Med. 2020;383(3):240-251.

15. Liberati A, Altman DG, Tetzlaff J, Mulrow C, Gotzsche PC, loannidis JP, Clarke M, Devereaux PJ, Kleijnen J, Moher D. The PRISMA statement for reporting systematic reviews and meta-analyses of studies that evaluate health care interventions: explanation and elaboration. PLoS Med. 2009;6(7):e1000100.

16. Higgins JP, Altman DG, Gotzsche PC, Juni P, Moher D, Oxman AD, Savovic J, Schulz KF, Weeks L, Sterne JA, et al. The Cochrane Collaboration's tool for assessing risk of bias in randomised trials. BMJ. 2011;343:d5928.

17. Higgins JP, Thompson SG, Deeks JJ, Altman DG. Measuring inconsistency in meta-analyses. BMJ. 2003;327(7414):557-60.

18. Egger M, Davey Smith G, Schneider M, Minder C. Bias in meta-analysis detected by a simple, graphical test. BMJ. 1997;315(7109):629-34.

19. Vincent JL, Moreno R, Takala J, Willatts S, De Mendonca A, Bruining H, Reinhart CK, Suter PM, Thijs LG. The SOFA (Sepsis-related Organ Failure Assessment) score to describe organ dysfunction/failure. On behalf of the Working Group on Sepsis-Related Problems of the European Society of Intensive Care Medicine. Intensive Care Med. 1996;22(7):707-10.

20. Gaudry S, Hajage D, Schortgen F, Martin-Lefevre L, Pons B, Boulet E, Boyer A, Chevrel G, Lerolle N, Carpentier D, et al. Initiation strategies for renal-replacement therapy in the intensive care unit. N Engl I Med. 2016;375(2):122-33.

21. Wetterslev J, Jakobsen JC, Gluud C. Trial sequential analysis in systematic reviews with meta-analysis. BMC Med Res Methodol. 2017;17(1):39.

22. Barbar SD, Clere-Jehl R, Bourredjem A, Hernu R, Montini F, Bruyere R, Lebert C, Bohe J, Badie J, Eraldi JP, et al. Timing of renal-replacement therapy in patients with acute kidney injury and sepsis. N Engl J Med. 2018:379(15):1431-42.

23. Combes A, Brechot N, Amour J, Cozic N, Lebreton G, Guidon C, Zogheib E, Thiranos JC, Rigal JC, Bastien O, et al. Early high-volume hemofiltration versus standard care for post-cardiac surgery shock. The HEROICS Study. Am J Respir Crit Care Med. 2015;192(10):1179-90.

24. Zarbock A, Kellum JA, Schmidt C, Van Aken H, Wempe C, Pavenstadt H, Boanta A, Gerss J, Meersch M. Effect of early vs delayed initiation of renal replacement therapy on mortality in critically III patients with acute kidney injury: the ELAIN randomized clinical trial. JAMA. 2016;315(20):2190-9.

25. Lumlertgul N, Peerapornratana S, Trakarnvanich T, Pongsittisak W, Surasit K, Chuasuwan A, Tankee P, Tiranathanagul K, Praditpornsilpa K, Tungsanga $K$, et al. Early versus standard initiation of renal replacement therapy in furosemide stress test non-responsive acute kidney injury patients (the FST trial). Crit Care. 2018;22(1):101.

26. Srisawat $N$, Laoveeravat $P$, Limphunudom $P$, Lumlertgul N, Peerapornratana S, Tiranathanagul K, Susantitaphong P, Praditpornsilpa K, Tungsanga $\mathrm{K}$, Eiam-Ong $\mathrm{S}$. The effect of early renal replacement therapy guided by plasma neutrophil gelatinase associated lipocalin on outcome of acute kidney injury: a feasibility study. J Crit Care. 2018;43:36-41.

27. Wald R, Adhikari NK, Smith OM, Weir MA, Pope K, Cohen A, Thorpe K, Mclntyre L, Lamontagne F, Soth M, et al. Comparison of standard and accelerated initiation of renal replacement therapy in acute kidney injury. Kidney Int. 2015;88(4):897-904. 
28. Jamale TE, Hase NK, Kulkarni M, Pradeep KJ, Keskar V, Jawale S, Mahajan D. Earlier-start versus usual-start dialysis in patients with communityacquired acute kidney injury: a randomized controlled trial. Am J Kidney Dis. 2013;62(6):1116-21.

29. Bouman CS, Oudemans-Van Straaten HM, Tijssen JG, Zandstra DF, Kesecioglu J. Effects of early high-volume continuous venovenous hemofiltration on survival and recovery of renal function in intensive care patients with acute renal failure: a prospective, randomized trial. Crit Care Med. 2002;30(10):2205-11.

30. Xia Y, Shi H, Wu W, Wang X. Effect of urinary NGAL on the timing of renal replacement therapy in patients with acute renal injury associated with sepsis. Med J Chin PLA. 2019;44(7):605-10.

31. Seabra VF, Balk EM, Liangos O, Sosa MA, Cendoroglo M, Jaber BL. Timing of renal replacement therapy initiation in acute renal failure: a metaanalysis. Am J Kidney Dis. 2008;52(2):272-84.

32. Liu Y, Davari-Farid S, Arora P, Porhomayon J, Nader ND. Early versus late initiation of renal replacement therapy in critically ill patients with acute kidney injury after cardiac surgery: a systematic review and meta-analysis. J Cardiothorac Vasc Anesth. 2014;28(3):557-63.

33. Feng YM, Yang Y, Han XL, Zhang F, Wan D, Guo R. The effect of early versus late initiation of renal replacement therapy in patients with acute kidney injury: A meta-analysis with trial sequential analysis of randomized controlled trials. PLoS ONE. 2017;12(3):e0174158.

34. Moreira FT, Palomba H, Chaves RCF, Bouman C, Schultz MJ, Serpa Neto A. Early versus delayed initiation of renal replacement therapy for acute kidney injury: an updated systematic review, meta-analysis, meta-regression and trial sequential analysis of randomized controlled trials. Rev Bras Ter Intensiva. 2018;30(3):376-84.

35. Douvris A, Malhi G, Hiremath S, Mclntyre L, Silver SA, Bagshaw SM, Wald R, Ronco C, Sikora L, Weber C, et al. Interventions to prevent hemodynamic instability during renal replacement therapy in critically ill patients: a systematic review. Crit Care. 2018;22(1):41.
36. Silversides JA, Pinto R, Kuint R, Wald R, Hladunewich MA, Lapinsky SE, Adhikari NK. Fluid balance, intradialytic hypotension, and outcomes in critically ill patients undergoing renal replacement therapy: a cohort study. Crit Care. 2014;18(6):624.

37. Douvris A, Zeid K, Hiremath S, Bagshaw SM, Wald R, Beaubien-Souligny W, Kong J, Ronco C, Clark EG. Mechanisms for hemodynamic instability related to renal replacement therapy: a narrative review. Intensive Care Med. 2019;45(10):1333-46.

38. Reynvoet E, Vandijck DM, Blot SI, Dhondt AW, De Waele JJ, Claus S, Buyle FM, Vanholder RC, Hoste EA. Epidemiology of infection in critically ill patients with acute renal failure. Crit Care Med. 2009;37(7):2203-9.

39. Hoste EA, Blot SI, Lameire NH, Vanholder RC, De Bacquer D, Colardyn FA. Effect of nosocomial bloodstream infection on the outcome of critically il patients with acute renal failure treated with renal replacement therapy. J Am Soc Nephrol. 2004;15(2):454-62.

40. Shaw AR, Mueller BA. Antibiotic Dosing in Continuous Renal Replacement Therapy. Adv Chronic Kidney Dis. 2017;24(4):219-27.

41. Kamboj M, Kazory A. Expanding the Boundaries of Combined Renal Replacement Therapy for Non-Renal Indications. Blood Purif. 2019;47(1-3):69-72

42. Cardoso FS, Gottfried M, Tujios S, Olson JC, Karvellas CJ. Group USALFS: Continuous renal replacement therapy is associated with reduced serum ammonia levels and mortality in acute liver failure. Hepatology. 2018;67(2):711-20.

\section{Publisher's Note}

Springer Nature remains neutral with regard to jurisdictional claims in published maps and institutional affiliations.
Ready to submit your research? Choose BMC and benefit from:

- fast, convenient online submission

- thorough peer review by experienced researchers in your field

- rapid publication on acceptance

- support for research data, including large and complex data types

- gold Open Access which fosters wider collaboration and increased citations

- maximum visibility for your research: over 100M website views per year

At BMC, research is always in progress.

Learn more biomedcentral.com/submissions 